\title{
Reservoir heterogeneity and fracture parameter determination using electrical image logs and petrophysical data (a case study, carbonate Asmari Formation, Zagros Basin, SW Iran)
}

\author{
Ghasem Aghli $^{1} \cdot$ Reza Moussavi-Harami ${ }^{2} \cdot$ Ruhangiz Mohammadian $^{1}$
}

Received: 8 March 2018 / Published online: 23 December 2019

(c) The Author(s) 2019

\begin{abstract}
Assessment of reservoir and fracture parameters is necessary to optimize oil production, especially in heterogeneous reservoirs. Core and image logs are regarded as two of the best methods for this aim. However, due to core limitations, using image $\log$ is considered as the best method. This study aims to use electrical image logs in the carbonate Asmari Formation reservoir in Zagros Basin, SW Iran, in order to evaluate natural fractures, porosity system, permeability profile and heterogeneity index and accordingly compare the results with core and well data. The results indicated that the electrical image logs are reliable for evaluating fracture and reservoir parameters, when there is no core available for a well. Based on the results from formation micro-imager (FMI) and electrical micro-imager (EMI), Asmari was recognized as a completely fractured reservoir in studied field and the reservoir parameters are mainly controlled by fractures. Furthermore, core and image logs indicated that the secondary porosity varies from $0 \%$ to $10 \%$. The permeability indicator indicates that zones 3 and 5 have higher permeability index. Image log permeability index shows a very reasonable permeability profile after scaling against core and modular dynamics tester mobility, mud loss and production index which vary between 1 and 1000 md. In addition, no relationship was observed between core porosity and permeability, while the permeability relied heavily on fracture aperture. Therefore, fracture aperture was considered as the most important parameter for the determination of permeability. Sudden changes were also observed at zones 1-1 and 5 in the permeability trend, due to the high fracture aperture. It can be concluded that the electrical image logs (FMI and EMI) are usable for evaluating both reservoir and fracture parameters in wells with no core data in the Zagros Basin, SW Iran.
\end{abstract}

Keywords FMI and EMI image logs $\cdot$ Porosity and permeability $\cdot$ Fractures $\cdot$ Core data $\cdot$ Heterogeneity index

\section{Introduction}

Direct and indirect methods are available to detect fractures in reservoirs (Thompson 2000). Core and image logs are the most common and direct methods for the evaluation of fracture and reservoir parameters (porosity and permeability), although core sampling can suffer from important limitations such as high coring cost, low recovery factor and

Edited by Jie Hao and Xiu-Qiu Peng

Ghasem Aghli

Aghli@ferdowsi.um.ac.ir

1 National Iranian South Oil Company (NISOC), Ahvaz, Iran

2 Department of Geology, Ferdowsi University of Mashhad, Mashhad, Iran uncertainty in the core direction (Khoshbakht et al. 2012; Lyu et al. 2016). Image logs have become recognized as the most important borehole logging technique for fractured reservoir evaluation, and they have developed rapidly due to their excellent performance in characterizing borehole features such as fractures and bedding (Serra and Serra 2004a, b; Tingay et al. 2008). Furthermore, the use of image logs has decreased overall costs by reducing coring intervals and by accurately determining the perforation zones (Aghli et al. 2017). In the carbonate formations, fractures, even very fine ones, strongly influence permeability (Lavenu et al. 2014) and understanding their distribution patterns can help to determine the best locations for drilling and maximizing production (Serra and Serra 2004a, b). Indeed, fractures play a pivotal role in controlling the migration of oil in the Zagros Basin (Alavi 2004, 2007). 
Fracture evaluation is very important in the carbonate reservoirs, particularly fractured reservoir due to the high impact of fractures on the reservoir permeability (Nelson 2001; Van der Land et al. 2013). Actually, fractured reservoirs are usually known with their low relation between primary porosity and permeability trend. Imaging tools may use either electrical or ultrasonic measurements, but in this study we focus only on the electrical one because of its more abilities. Electrical image logging tools that can evaluate the role of fractures in reservoir performance include the formation micro-imager (FMI) (Serra 1989; Schlumberger 2003) and the electrical micro-imager (EMI) (Halliburton 1996). As a result, fracture diagnosis remains merely qualitative, unless these tools are used to determine reservoir porosity and permeability (Aghli et al. 2016; Hornby et al. 1992; Lai et al. 2017a; Martinez et al. 2002). Most previous studies have focused on image logs for the identification of features in reservoir rocks (Khoshbakht et al. 2009; Miller et al. 2003; Zazoun 2013). Luthi and Souhaite (1990) pioneered to estimate of fracture aperture using electrical image logs, and Akbar et al. (2003) used FMI to determine the reservoir porosity in the Arab Formation of Iran. Later, Witherspoon (2010) introduced a new formula for calculating fracture permeability by using a cubic relation based on aperture. By building on previous studies, the present study aims to determine fracture-controlled reservoir properties from FMI and EMI logs, which can be implemented in wells without core data. We show that fracture evaluation is an important step in the evaluation of heterogeneous carbonate reservoirs, especially where permeability trend is not describable by core data because of secondary porosity. In the present study, we estimate porosity and permeability with high resolution $(2.5 \mathrm{~mm})$ for all well intervals in the Asmari Formation in SW Iran and determine reservoir parameters such as fractures and heterogeneity index. We also validate our results with other dependable data sources. We conclude that image logs may be used for quantitative evaluation of reservoir porosity and permeability by analysis of fracture aperture, as a substitute for core data in wells without core.

\section{Geological setting of the study area}

The studied oil field is located in the southern parts of the Dezful Embayment in SW Iran.

Dezful Embayment is a petroliferous part of the Zagros fold-thrust belt (Alavi 2007; McQuillan 1974). Zagros fold-thrust belt is formed during collision between the Iranian and Arabian plates, starting during the Late Cretaceous time and expedited during the Late Miocene and Pliocene time (Stocklin 1968). This convergence between Iranian and Arabian plates is still active via NNE-SSW stress direction (DeMets et al. 2010). The Asmari Formation is composed of light gray to white shallow marine limestones (grainstone, pelletal packstone and bioclastic wackestone) with intercalations of black fissile shale and anhydrite (Alavi 2004). This formation is known as one of the major reservoirs in the Dezful Embayment and one of the typical fractured reservoirs in the world (Nelson 2001). The studied wells are located at the western part of the studied field in Khuzestan Province near the strike-slip and main reverse faults (Fig. 1). The presence of a major reverse fault in the southern edge as well as several strike-slip faults represented an active tectonic in this oil field (NISOC Management 2010, personal communication). Also, axis recirculation and higher dip of layers in the southern edge are detectable on the UGC map, particularly in the SW part (near well No. 126). These are the reasons that we focused on a potentially fractured and heterogeneous reservoir in that area.

\section{Methods and material}

The main data available for this research are electrical image logs (FMI in well No. 126 and EMI in well No. 125) and core data. Also, conventional logs, modular dynamics tester (MDT) mobility, mud loss and production data were used as auxiliary data for validation. Figure 2 illustrates the designed flowchart of the study. Generally, cores considered as the main data to identify reservoir parameters and geological features.

\subsection{Image log}

FMI image tool with totally 192 electrode buttons ( $80 \%$ coverage) and EMI via 150 buttons (60\% coverage) are very appropriate devices for formation evaluation (Aghli et al. 2014; Chen and Wang 2017).

Fractures, bedding and other sedimentary features, i.e., stylolite and conductive seams, are the main types of geological structures which are recognizable by image logs (Lai et al. 2017b). The features are particularly evident on the electrical images due to strong resistivity contrast between them. Therefore, the dip of sedimentary features, e.g., bedding is easily detectable using electrical image logs, especially when the formation is in the normal condition and stratified. The formation resistivity directly depends on the sequences of tight and porous layers. Diagenetic processes can result in creating some irregular bedding and fracture planes in a few intervals, complicating the precise determination of the structural dip. Some intervals that strongly affected by diagenetic processes were identified in the Asmari Formation, where the image logs or cores revealed thinly bedded or high heterogeneity index. 


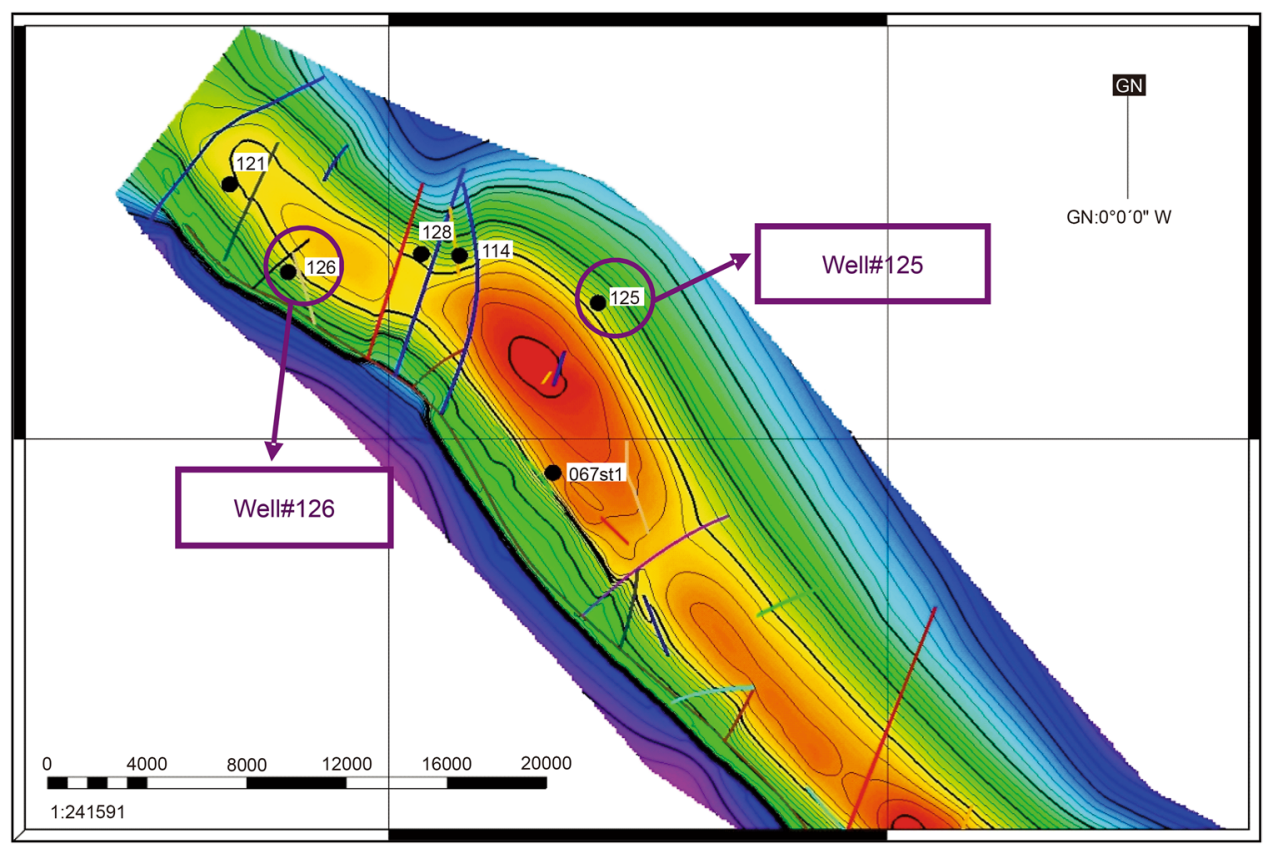

Fig. 1 Underground contour map (UGC) at the top of Asmari Formation in the studied field with location of studied wells (provided by NISOC). Well No. 126 located between main thrust and two strike-slip faults

\subsubsection{Natural fracture analysis and fracture aperture using electrical image logs}

Fractures are recognized as the features with no block displacement along their planes (Schlumberger 2005). Generally speaking, according to Movahed et al. (2015a, b), they show a high dip in the tensional and wrench regimes. Further, aperture plays an inevitable role in the fracture evaluation, involving open (for fluid flow determination), closed or filled (for studding previous affected events on the reservoir) (Ameen et al. 2012). On the image logs, fractures are displayed as sinusoid features with more dip than structural dip (Fig. 3). Open fractures represent a conductive appearance on the electrical images, because their aperture is filled with the conductive drilling mud, i.e., in a clay free formation. However, the appearance for closed or filled fractures is resistive if the filling materials are dense like calcite or anhydrite. In some cases, full set logs such as PEF, RHOZ, resistivity $\log$ s and NPHI are very useful for such kind of differentiation (Saboorian-Jooybari et al. 2015; Tokhmchi et al. 2010).

It is noteworthy that fracture aperture is only measurable using some electrical imaging tools (not all image $\log$ ) for open fractures. However, a new method has recently been introduced for permeability determination by ultrasonic image tools (de Jesus et al. 2016). Fracture aperture is calculated using Eq. (1) which introduced by Luthi and Souhaite (1990):
$W=c \cdot A \cdot R m^{b} \cdot R x o^{1-b}$

where ' $W$ ' is fracture aperture (mm), ' $A$ ' is an access flow of each electrode, ' $R m$ ' is the resistivity of drilling mud (ohm), ' $R x o$ ' indicates the resistivity of the invaded zone (ohm), and $\mathbf{c}$ and $\mathbf{b}$ are constants, based on the tool and environmental properties. In general, $A$ represents the additional current which may be injected through the formation divided by the voltage, integrated along a line perpendicular across the fracture trace.

Both constants $\mathrm{c}$ and $\mathrm{b}$ are obtained from forward modeling numerically, and their values are related to each image tool feature. Coefficient $\mathrm{c}$ is related to a geometric factor, integrating the measured resistance to the actual formation resistivity. Exponent $\mathrm{b}$ indicates the sensitivity of $A$ to the resistivity contrast between formation and borehole mud, and its value is primarily influenced by the amount of current focusing as a function of the resistivity contrast and the borehole diameter. In order to focus equally, $b$ is assumed as 1 in all resistivity regimes and borehole sizes. Thus, the exponent $\mathrm{b}$ was found to be relatively close to 1 . The added conductance $A$ is primarily dominated by the aperture and the fluid in the fracture and, to a lesser degree, by the resistivity of the formation in which fracture occurs.

According to the equation, the measured fracture aperture depends on the resistivity of the drilling mud ( $\mathrm{Rm})$ and invaded zone (Rxo) variables. An increase takes place in the current due to low resistivity where a tool button 


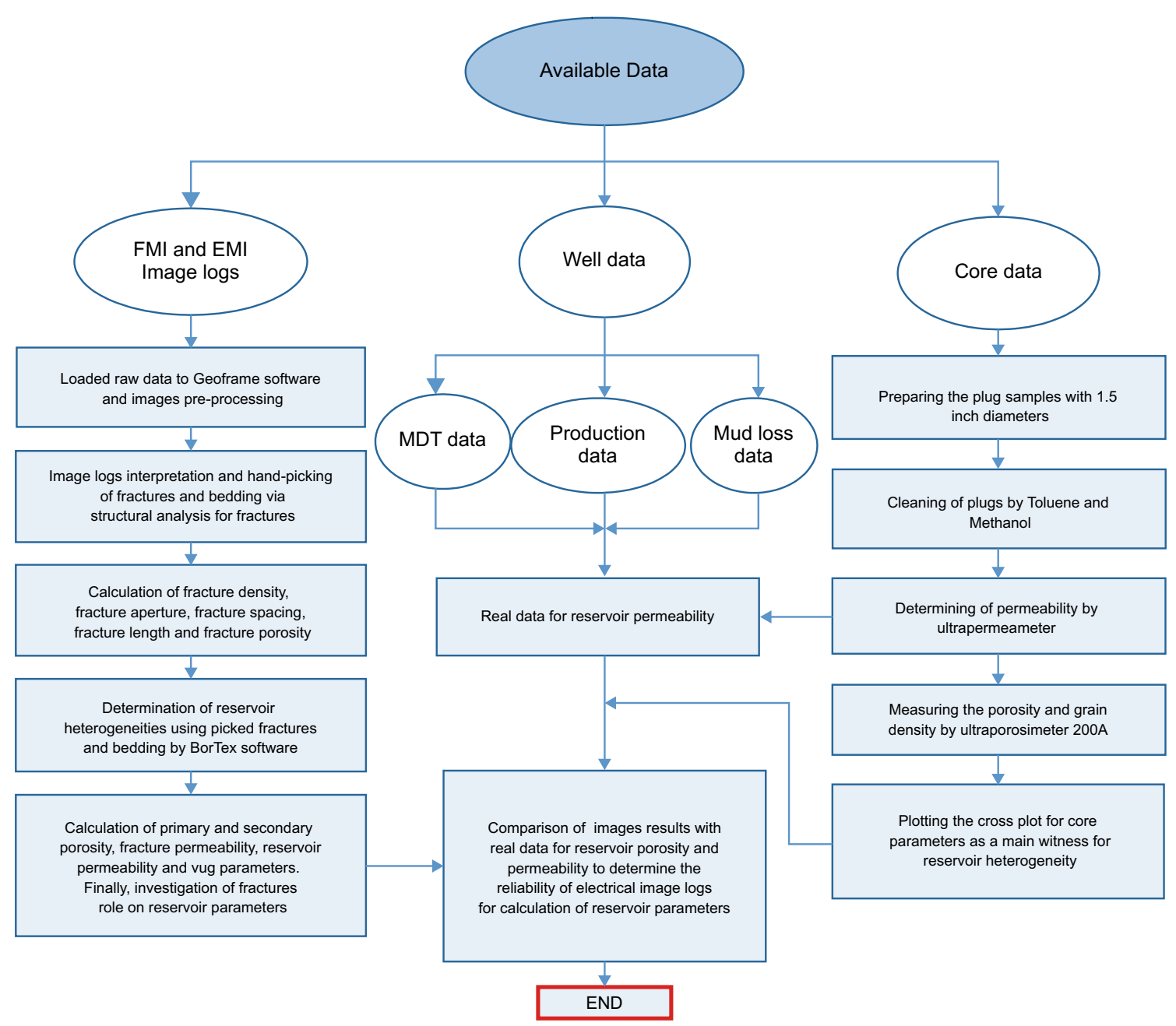

Fig. 2 Flowchart for the evaluation of electrical image log reliability for the determination of reservoir parameters designed in this study

reaches an open fracture which filled with less dense mud or other fluids (Rm) (Fig. 4). The increased current proceeds to flow until electrode is far enough from the fracture. Therefore, the fracture, which is physically thinner than $0.1 \mathrm{~mm}$, may involve an electrical image which appears to be an inch or wider. Unfortunately, the image $\operatorname{logs}$ tend to exaggerate fracture aperture, particularly for small fractures. This is regarding the minimum size that a fracture can be detected on a log due to the pixel density, spacing of electrodes and erosion of the wellbore by fractures. Obviously, detecting a fracture is directly impossible by a sensor button which is many times higher than the size of fracture, although some indirect methods can be used to solve the problem. Measurement and mathematical simulation are used to find the response of the electrical image tool to the fracture filled with fluids including different resistivities. Moreover, the fractures are equal to the total of the increased current flow.

\subsubsection{Secondary porosity and high-resolution porosity}

In most carbonate reservoirs, porosity from density and neutron logs cannot be used for the interpretation of the large amount of hydrocarbon production. For example, the zones with low porosity provide good production indices and vice versa (Akbar et al. 2003; Rezaee and Chehrazi 2005). All electrical image logs, especially FMI and EMI, can quantitatively resolve the heterogeneous nature and porosity components of reservoirs via the high resolution and azimuthal coverage (see Figs. 5, 6, 7). For this aim, Porosity Spectrum Analysis (PoroSpect) as a textural analysis technique was used that gives porosity distribution and vug fraction quantification from high-resolution electrical borehole images such as FMI. The primary assumption for this technique is that the conductivity measurement from the electrical images is taken from the flushed zone of the borehole. After calibration with a shallow resistivity $\log$, the conductivity images are transformed into a 


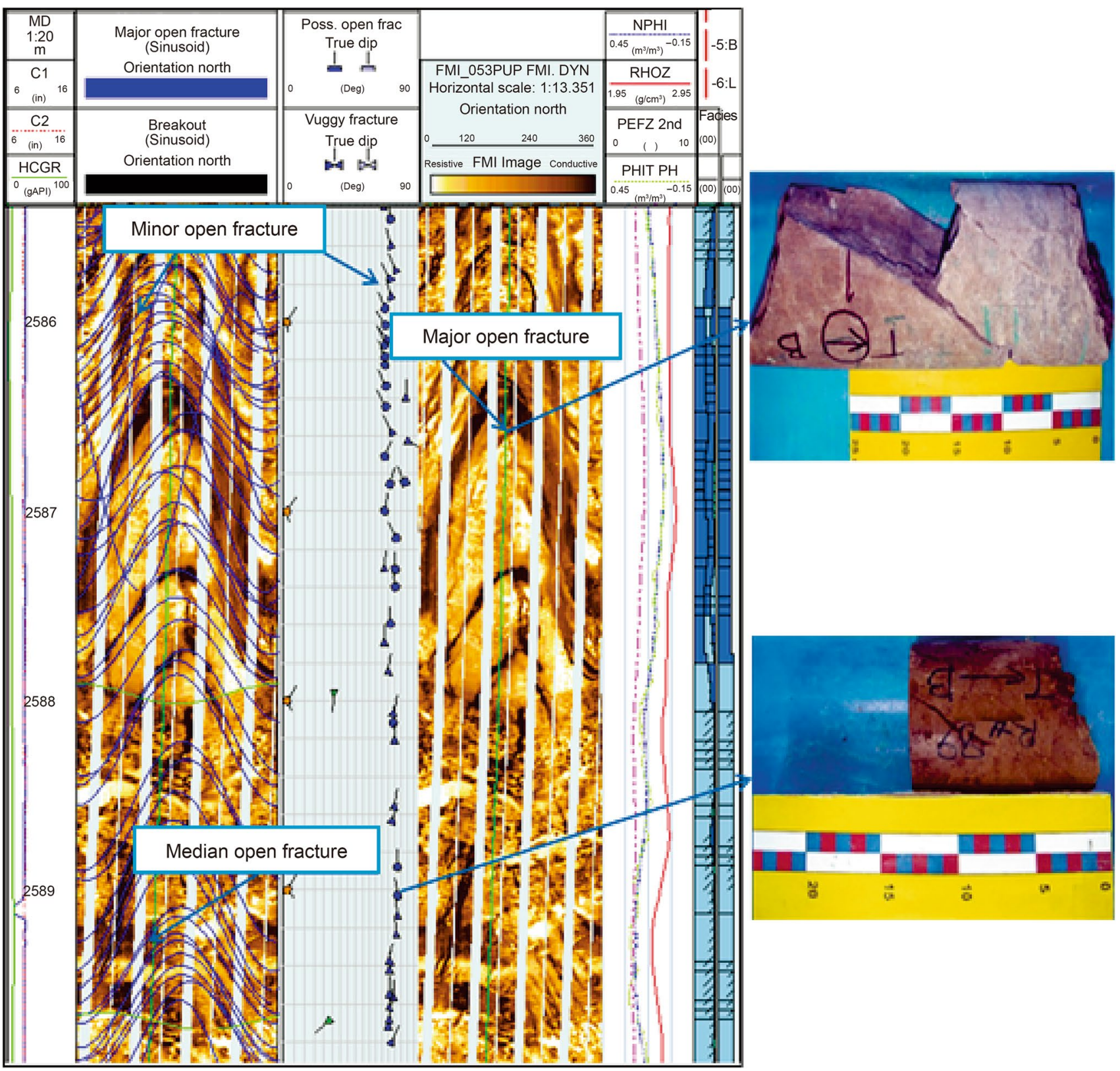

Fig. 3 Minor open fractures (blue triangle dips), medium open fractures (blue circular dips) and major open fractures (blue square dips) shown by FMI image and core in zone 3 of Asmari Formation

porosity map of the borehole using log porosity by the mentioned equation. For the first time, Akbar et al. (2000) practically used electrical image logs for the porosity system analysis in the carbonate reservoirs and introduced Eq. 2. Based on this equation, effective log porosity (or other porosity logs), shallow resistivity measurement (generally LLS or RLA3) and conductivity for each electrode $(\mathrm{C} i$ ) are used.

$\emptyset_{\mathrm{FMI} / \mathrm{EMI}}=\emptyset_{\log } \times[L L S \times C i]^{1 / m}$ where $C i$ represents the conductivity of each of the FMI/ EMI electrodes (1/ohm), LLS is the resistivity curve of external shallow flushed zone, $\phi_{\log }$ is the external porosity curve like NPHI, and $m$ is Archie cementation factor (2-2.5 for carbonate reservoirs).

By this equation, electrical image logs are used to calculate the distribution of porosity and quantity of vugs. Nevertheless, shale interbeds and bad hole conditions are considered as two main problems arising from using the aforementioned technique which can largely influence on the results of this method. Measuring the resistivity data in 


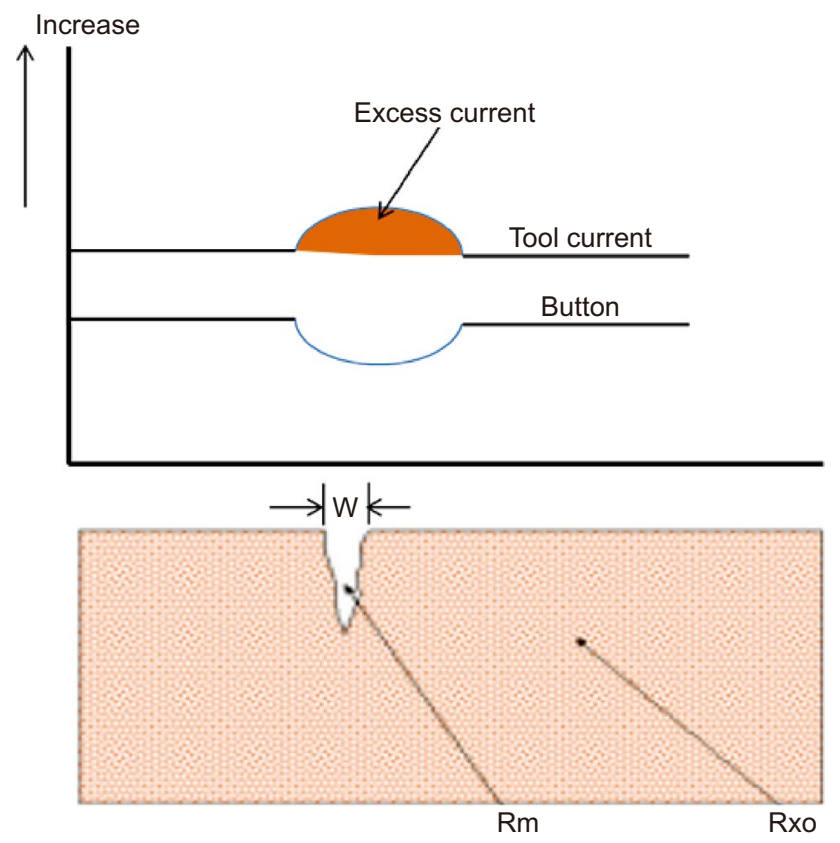

Fig. 4 Calculation of fracture aperture; fracture which is physically thinner than $0.1 \mathrm{~mm}$ may have an electrical image which appears to be an inch or more wide (Hornby et al. 1992)

the flushed zone through the electrical images is regarded as one of the basic assumptions for using the new technique in the present study; therefore, distribution map for porosity is constructed by using the electrical images after calibration with the resistivity and other porosity logs (Fig. 6). Based on the applied equation, the accuracy of porosity results in the image logs is a function of accuracy of conventional porosity logs. (This formula has been introduced for FMI, but is similarly applicable for EMI.)

\subsubsection{Image permeability}

In order to calculate the permeability from electrical image logs, the conductive connected heterogeneities (red spots in Fig. 7a) and heterogeneity indexes should be determined. For this aim, the extracted fractures and bedding dip data were imported into the software. Then, the heterogeneity analysis of reservoir from electrical images was used to extract the heterogeneity and layer details (Movahed et al. 2015a). The various heterogeneities on the electrical image logs are specified, and connections were harmonized to the conductive links at the matrix level between the conductive events (thin yellow lines in Fig. 7a). By computing the amount of additional conductivity due to such thin conductive routes, a connectedness coefficient (henceforth called raw FMI/ FMI permeability indicator) was computed, which is transformed into absolute permeability after its comparison with the cores or MDT over some short intervals (Movahed et al. 2015b) (Fig. 7b). In this study, where images conductivity is largely influenced by reservoir fluids and shale contents, the raw calculated permeability indicator is emended with some normalization functions such as water saturation ( $\mathrm{Sw}$ and Sxo), porosity and shale volume. The permeability of fractured reservoirs is actively dominated by the open fracture permeability (Chandra et al. 2015a, b). Matrix and fracture porosity and permeability are different according to rock type and fracture morphology (Witherspoon 2010). Fracture permeability is calculated by using Eq. (3):

$K_{f=f} \frac{e^{3}}{12}$

where $K_{f}$ represents the fracture permeability (md), $f$ is the total fracture length per unit cross section $(\mathrm{mm})$ and $e$ is the fracture aperture $(\mathrm{mm})$. As mentioned above, there is an exaggeration in computing aperture with image logs. The fracture frequency may also be exaggerated if the dip correlation processing picks the same fracture at different depths. Further, like the result of this research, calculated fracture frequency will be more reliable if fracture dips determine by handpicking. The calculated reservoir permeability is extended for the entire formation intervals after correlation with other valid data. However, the accuracy of the normalization relies on the accuracy of the variables such as water saturation, porosity and clay volume, used in the normalization function which is driven by three main factors including fracture spacing, fracture aperture and the way of connecting the fractures (Özkaya 2003). The fracture spacing and aperture are utilized to estimate the fracture permeability. Fracture results in compressing or reducing porosity and permeability much more readily than the matrix with increasing stress. Accordingly, the porosity and permeability of fractures are more vulnerable to reservoir depletion.

\subsection{Core description}

Core data, e.g., porosity, permeability and grain density are regarded as the most dependable data set for reservoir characterization. In this study, 355-meter core is available from the Asmari Formation with $65 \%$ core recovery.

Nevertheless, these data are only accessible for coring intervals, which is considered as the main weak point for core data, especially in the heterogeneous reservoirs. The experiments were performed on core-plug samples with 1.5 inch diameter. Samples were cleaned to remove residual hydrocarbons, formation brine, salts and other contaminants by using toluene and methanol; then, they were dried in a conventional oven. Porosity and grain density of samples were measured in ambient condition using helium expansion and the application of Boyles's law to quantify grain volume. Air permeability was measured in ambient condition, which 


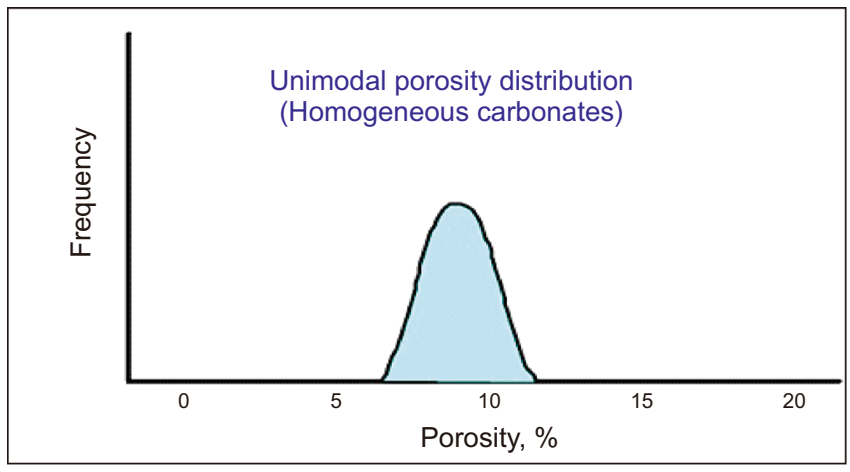

A


Fig. 5 Typical FMI porosity histograms show porosity distributions in homogeneous and heterogeneous carbonates. Unimodal distribution is found in homogeneous carbonates (a). Bimodal to trimodal distributions are found in heterogeneous carbonates (b and c). The porosity component due to vugs and fractures is obtained by applying an empirical cutoff to the porosity histograms (Akbar et al. 2000)

uses Darcy equation to calculate air permeability. In these wells, unfortunately gamma log of core was not available. However, some sharp features including anhydrite and shale thin layers, sedimentary structures and main open fractures were used for depth matching between core and image log data. Shifting of depth for core data varies from +1 to +1.5 $\mathrm{m}$. Also, cross-plot of core parameters is used as the main proof for reservoir heterogeneity. As illustrated in Fig. 8, low regression between core porosity and permeability indicates the high heterogeneity index in this reservoir. These crossplots indicate that permeability may be controlled by the secondary porosity in this reservoir. Furthermore, the cores were considered for detecting the fractures, but the number of detected fractures on core is much less than the image logs, due to low recovery factor of core. For example, almost 200 open fractures were determined in well No. 125 (520 on the image log), which dominant strike on N50W-S50E.

\subsection{Well test and production data}

Final results should be compared with real data in order to evaluate their accuracy. Therefore, well data including MDT data, mud loss and production data are used as complementary methods to confirm the reliability of the obtained results from electrical image logs. MDT tool provides the measurement of fast and accurate pressure and permeability anisotropy, as well as high-quality fluid sampling. MDT may also be considered as a high valuable data in the fractured 


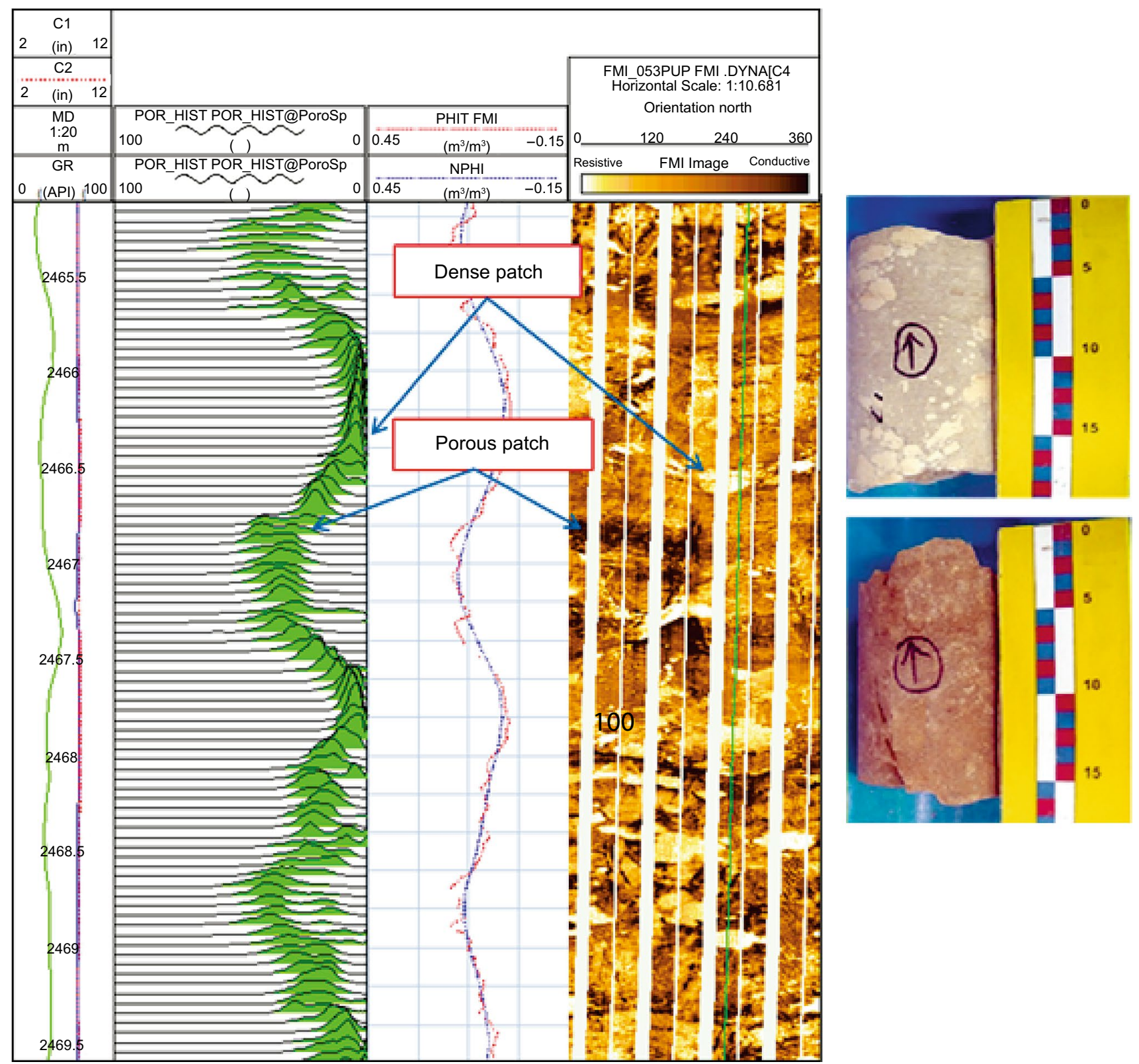

Fig. 6 Porosity histogram display over a section of Asmari (subzone 2-1). In this subzone, FMI has detected dense and porous patches that log porosity (NPHI and RHOB) did not identify them. Bimodal porosity histogram and core show secondary leached porosity

reservoirs where a change takes place in permeability due to the fracture existence. Equally, mud loss and production data are powerful witnesses for identification of fractured zones, especially those fractures with high aperture opening which creates a fracture network.

\section{Results and discussion}

After the analysis of image log and core data in the wells Nos. 125 and 126 (Fig. 1), several features such as fractures, bedding, induced fractures, borehole breakouts and stylolites were identified. Considering the importance of open fractures in this study, all their parameters were calculated and evaluated precisely. Then, these fractures were used for the evaluation of porosity and permeability systems. Results of each parameter are presented in the following sections.

\subsection{Fractures}

\subsubsection{Classification of fractures}

Based on the results of FMI and EMI logs, there are 1490 open and 90 closed fractures in well No. 126, while 520 


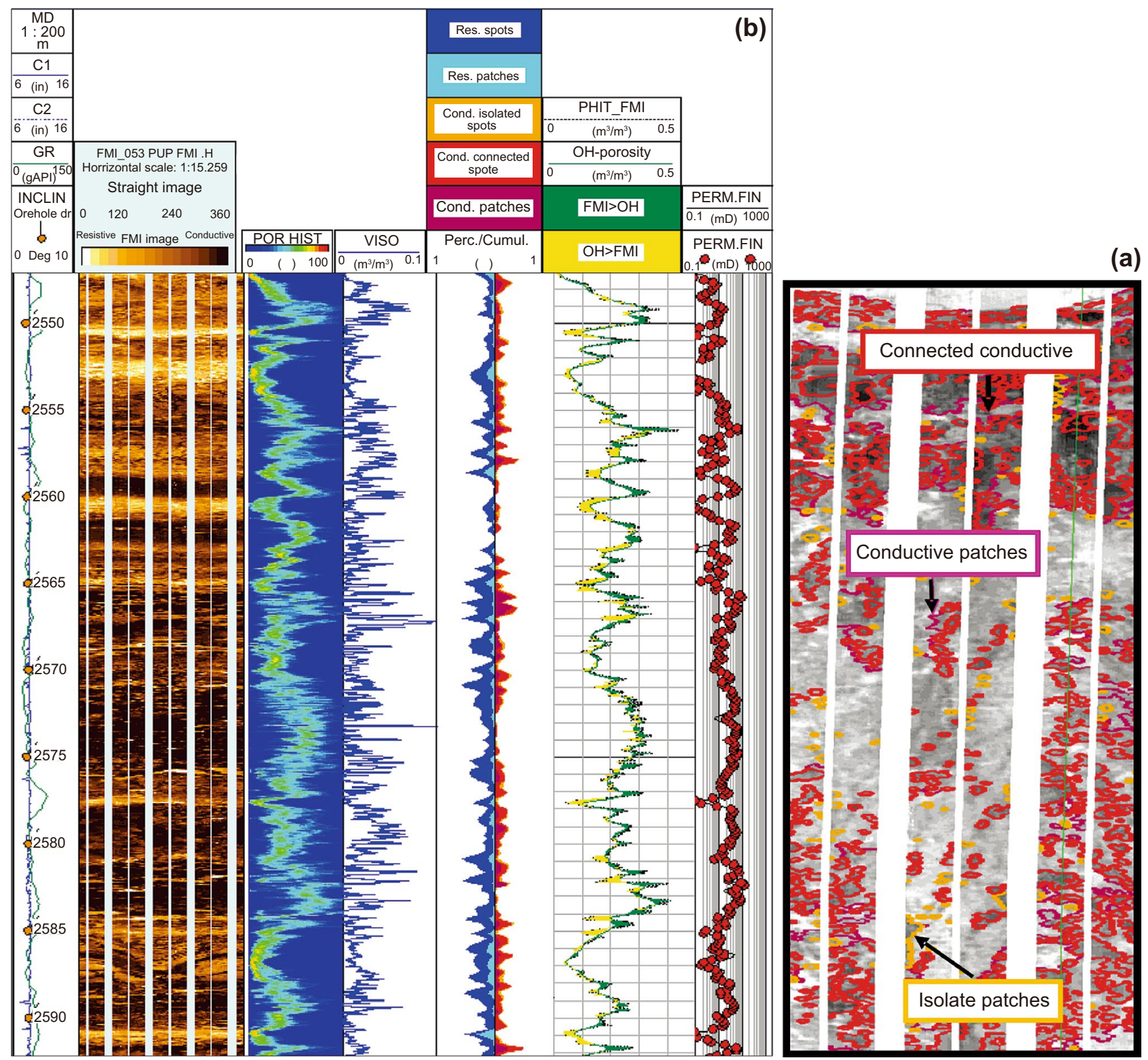

Fig. 7 a FMI calibrated images, highlighting conductive features comprising a section of Asmari Formation. Contoured/outlined in red are conductive connected spots (i.e., the features smaller than $0.0003 \mathrm{~m}^{2}$ ), in dark brown are isolated conductive spots, and in dark magenta are conductive patches (i.e., conductive features larger than $0.003 \mathrm{~m}^{2}$ ). b Result of porosity analysis in zone 5 of well No. 126 which show high permeability index

open and 50 closed fractures exist in well No. 125 (Fig. 9). As shown in Fig. 3, all open fractures show conductive and sinusoidal trace on the electrical image logs where all these traces may be continuous or discontinuous. Such fractures are different based on their aperture appearance and trace continuity across the wellbore. Therefore, as shown in Fig. 3, open fractures are classified into major open, minor open and medium open fracture categories. In well No. 126, there are 16 major open fractures, which are continuous across the wellbore and obviously involve large aperture, and 1358 medium open fractures, where their aperture is not as large as major open fractures, but their traces are still continuous. Some of discontinuous open fractures show a vuggy appearance, which is generally expected in carbonates rocks, due to dissolution of the host rock along the fracture plane as a result of crossing fluid. Thirty-six minor open fractures with low confidence were identified over the intervals and show a conductive appearance on FMI. In well No. 125, 12 major, 412 medium and 65 possible open fractures were determined. 

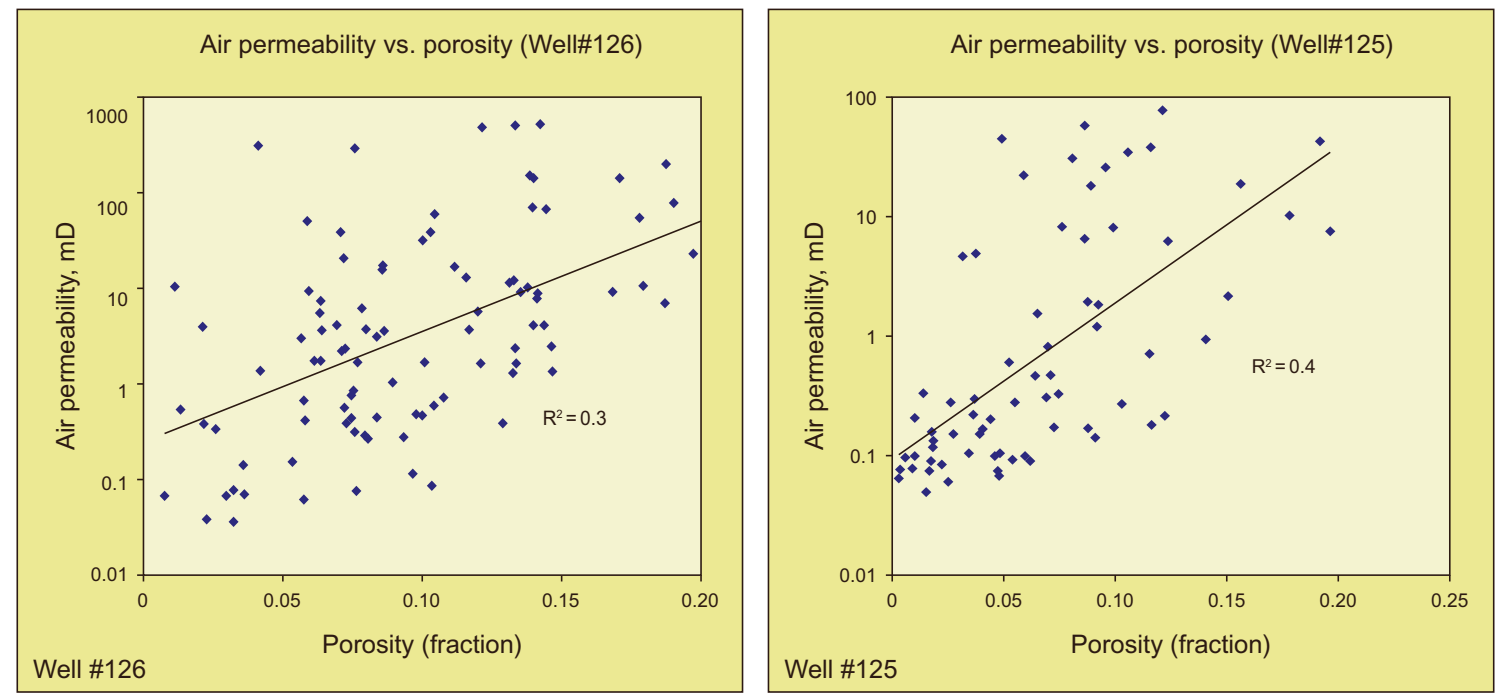

Fig. 8 Display of linear regression for core data in two studied wells. Low regression between core porosity and permeability indicates that permeability is controlled with secondary porosity
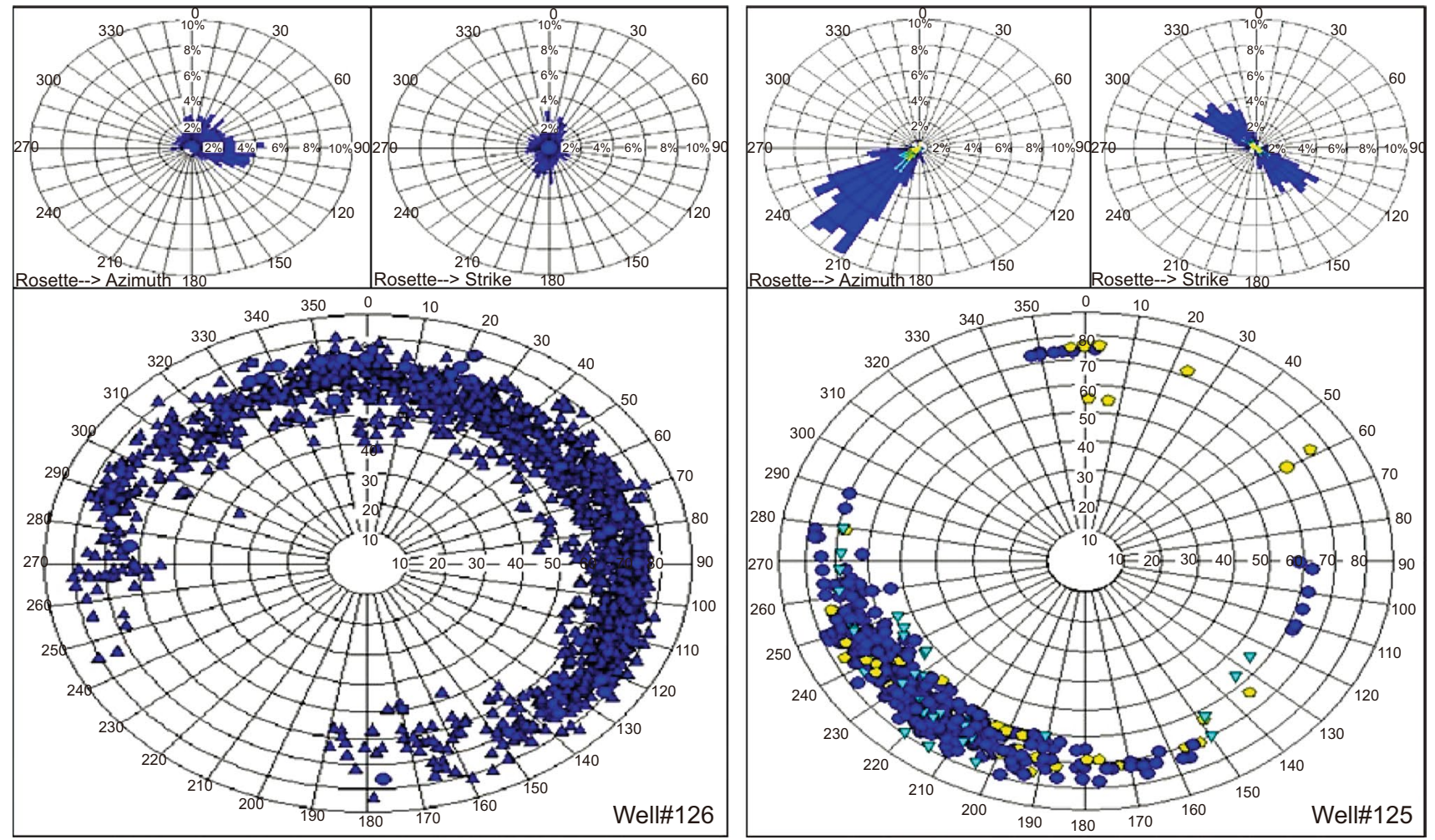

Fig. 9 Stereonet and rose diagram for all open fractures in the Asmari Formation in two studied wells. Well No. 126 has more fracture density because it is located near main thrust and two strike-slip faults

\subsubsection{Fracture dip/strike}

Most fractures are plotted within 50 to 80 degrees inclination circles of the stereonet in well No. 126. The open fractures in this well dominantly show strike of N11W-S11E with 69 dip inclination toward N79E, and in the well No. 125 , their strike is N50W-S50E with 50 dip inclination to S50W (Fig. 9). Our structural analyses indicate that the open 
fractures, based on their relation with the bedding strike, can classify to oblique, longitudinal and transverse types where longitudinal fractures are dominant type and they show the most fracture aperture as well. Oblique and transverse fractures are considered as faulting-related fractures and dominantly observed in well No. 126. While the well No. 125 is far away from the reverse and strike-slip faults, fractures are more longitudinal and their scatter pattern is more regular than well No. 126 (Fig. 9). Characteristics of all open fractures are given in Table 1 for well No. 126. The high number and outspread pattern of fractures in well No. 126 , undoubtedly, are related to the near faults of this well.

\subsubsection{Fracture porosity}

Fracture porosity is accurately measured by processing of electrical image logs. This parameter is a function of fracture density and fracture aperture (Ameen et al. 2012). The effect of fracture porosity on reservoir performance, however, is considerable due to its enormous contribution to permeability (Corbett et al. 2012). As a result, naturally fractured reservoirs behave differently than un-fractured reservoirs with similar porosity, due to the relative high flow capacity of the secondary porosity system. Fracture porosity usually has a very small values ranging between 0.0001 and 0.001 of rock volume and is typically $0.01 \%$ to $0.1 \%$. Fracturerelated porosity such as solution porosity in granite or carbonate reservoirs may attain much larger values (see zone 5 in Table 1), but the porosity in the actual fracture is insignificant. The ratio between fracture area (fracture length $\times$ fracture aperture) and the borehole area can be scanned by the electrical micro-images. Table 1 indicates the zones with different ranges of fracture porosity. The fracture porosity is displayed as percentage for well No. 126.

\subsubsection{Fracture aperture}

Data analyses for the calculation of the fracture aperture have already been presented in Sect. 3.1.1. In general, fracture aperture varies from $0.01 \mathrm{~cm}(0.1 \mathrm{~mm})$ in many places to $0.1 \mathrm{~cm}$ around zone 5 . Most fracture aperture is approximately $0.01 \mathrm{~cm}(1 \mathrm{~mm})$. Between the Asmari zones, fracture aperture shows the highest values around zones 3 and 5 (Figs. 10, 12 and Table 1).

\subsection{Porosity}

\subsubsection{Porosity system}

Based on the image logs, the accuracy of porosity values largely depends on the selection of accurate analytical methods for the fractures and vugs. Therefore, the related information about the type and size of secondary pores is required for the rocks to be evaluated with the imaging tools. In this regard, cores are available in the studied wells; therefore, data analysis was carried out in such a way that the whole range of macro-secondary pores could be addressed. Hence, a combination of core and image log data was used to detect the macro-secondary porosity (vugs/molds) and high-resolution porosity for Asmari Formation. The results of porosity (secondary and high-resolution porosity and porosity histogram) have been computed with 0.1 inch resolution for all reservoir intervals, which is so useful when compared to core porosity (only available for cored intervals). The results of porosity (secondary, minimum and maximum limits, and high-resolution porosities) from the studies well are displayed with 0.1 inch resolution (Figs. 10, 12). Based on the results of core analyses, primary porosity fails to control permeability and other parameters playing a significant role on its trend (Fig. 8).

Table 1 Summary of the characterization of fractured zones, mainly based on the mean porosity in the intervals

\begin{tabular}{|c|c|c|c|c|c|}
\hline Zone & Zone thickness, $\mathrm{m}$ & Number of fractures & Fracture density, $1 / \mathrm{m}$ & Fracture aperture, $\mathrm{cm}$ & $\begin{array}{l}\text { Fracture } \\
\text { porosity, } \mathrm{m}^{3} / \\
\mathrm{m}^{3}\end{array}$ \\
\hline Zone 1-1 & $2363-2396$ (27) & 148 & $0-50$ & $0-0.02$ & $0-0.002$ \\
\hline Zone 1-2 & 2396-2429 (33) & 150 & $0-50$ & $0-0.1$ & $0-0.005$ \\
\hline Zone 2-1 & 2429-2471 (42) & 227 & $0-50$ & $0-0.05$ & $0-0.002$ \\
\hline Zone 2-2 & $2471-2486.5(15.5)$ & 83 & $0-40$ & $0-0.05$ & $0-0.007$ \\
\hline Zone 3 & $2486.5-2530(43.5)$ & 142 & $0-42$ & $0-0.2$ & $0-0.005$ \\
\hline Zone 4 & $2530-2550.5(20.5)$ & 191 & $0-50$ & $0-0.07$ & $0-0.005$ \\
\hline Zone 5 & $2550.5-2585.5(35)$ & 235 & $0-50$ & $0-0.2$ & $0-0.025$ \\
\hline Zone 6-1 & $2585.5-2595(9.5)$ & 76 & $0-44$ & $0-0.1$ & $0-0.017$ \\
\hline Zone 6-2 & $2595-2605$ (10) & 67 & $0-35$ & $0-0.1$ & $0-0.005$ \\
\hline Zone $7-1$ & $2605-2655$ (50) & 169 & $0-30$ & $0-0.1$ & $0-0.008$ \\
\hline
\end{tabular}




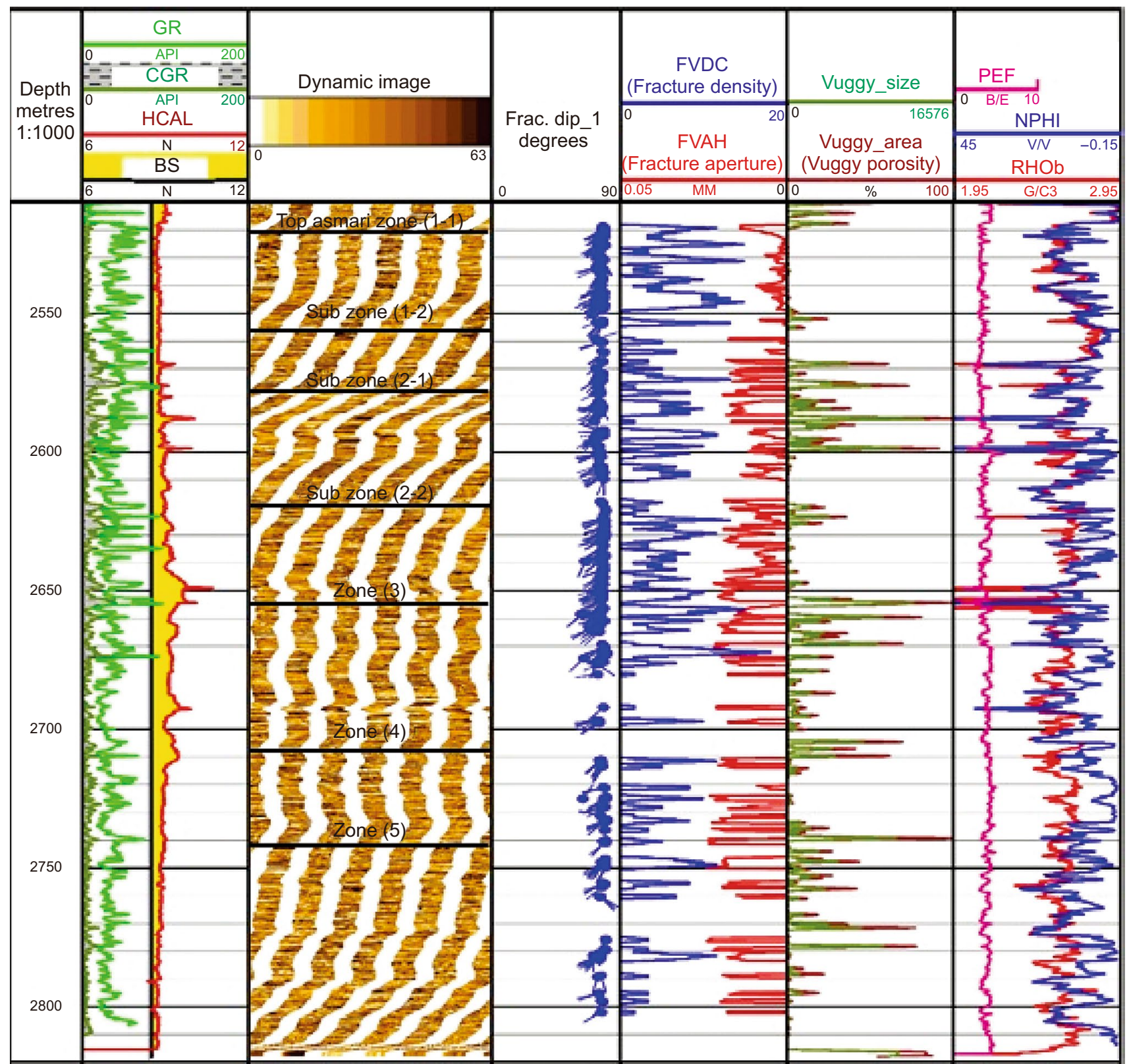

Fig. 10 Results for the determination of vuggy and fracture parameters in the well No. 125. Some zones with most of fracture density-such as zones 2-1 and 3-show the high vuggy parameters as well. This may indicate the role of vugs in the development of fractures

\subsubsection{Vuggy/moldic porosity}

There are some visible vugs and diagenetic features on the image $\log \mathrm{s}$ in the studied wells. The secondary porosity (possibly due to dissolution) varies from $0 \%$ to $10 \%$. In some intervals, such as zones 3 and 2-1, secondary porosity shows the best development (Fig. 10). It is important to note that, in the studied reservoir, vugs are definitely considered as a source of fractures which are known as vuggy fractures. As a result, zones with a high amount of fracture density, e.g., zones, 2-1 and 3, indicate high vuggy parameters as well, which can represent the role of vugs in the development of fractures. Also, the intervals with broader porosity distribution and more heterogeneity index show higher secondary porosity for the two wells (Figs. 11, 12).

\subsubsection{High-resolution porosity array}

The high-resolution porosity from electrical image logs is obtained from the average porosity map/histograms which are constructed from 96 porosity channels around the 



Fig. 11 An example plot for BorTex (software which used for extraction of heterogeneities from image logs). The highlighting type of information which displayed in the figure are formation average background and layer conductivities in Track 3; true stratigraphic thickness in Track 4 


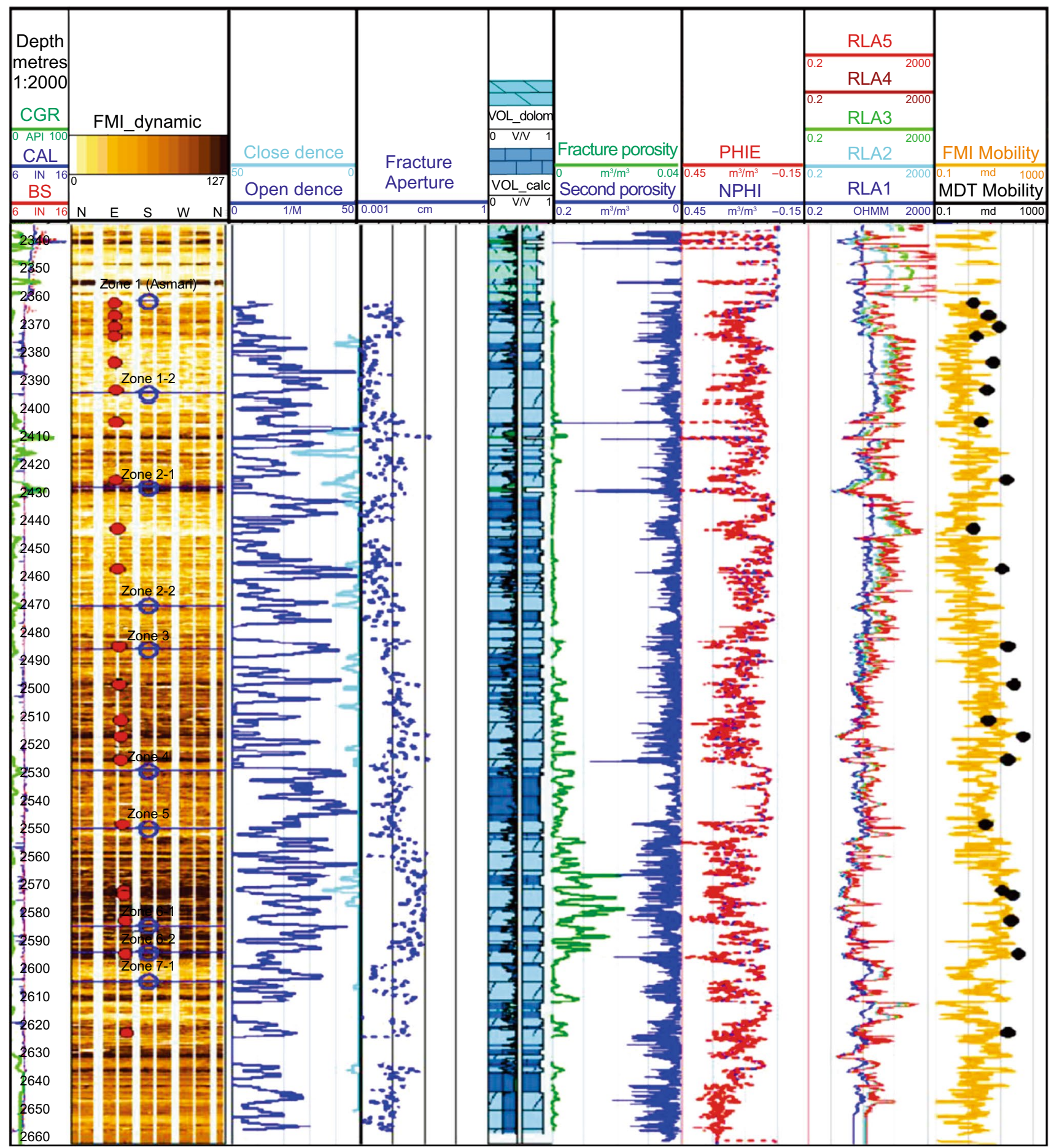

Fig. 12 Schematic plot for caliper logs (C1 and C2), HCGR, FMI static images, fracture parameters, lithology, porosity logs, resistivity logs, MDT mobility points and FMI raw permeability indicator for the Asmari Formation in well No. 126

wellbore. For the current study, the output at 0.1 inch was considered as depth sampling.

High- and low-porosity patches of smaller thicknesses, which no detectable by the conventional porosity logs, were highlighted during the high-resolution porosity analysis. The high resolution of FMI and EMI porosity was inclined to the neutron porosity corresponded over the homogenous zones, while reading more or less than the log porosity over the heterogeneous intervals having broader porosity distribution. Regarding the porosity histograms, most parts of the studied 
formation indicated high heterogeneity index in terms of porosity distribution, by wide porosity distribution, which confirmed by core data (Figs. 8, 11). However, some intervals included narrow and unimodal distribution of porosity.

\subsection{Reservoir heterogeneity}

The electrical image logs display heterogeneity in the form of conductive and dense areas for the all zones. In clean carbonates (most studied intervals), the conductive heterogeneities include different sizes, shapes and conductivities. The porous areas indicated different types such as patches of intergranular and intercrystalline porosity, vuggy porosity and open fractures. The conductive heterogeneities were largely observed in dense carbonate intervals due to clay seams and the presence of argillaceous material. The resistive heterogeneities showed low or zero porosity, due to dense and cemented areas, i.e., anhydrite and cemented zones. Observations, based on heterogeneity variations, are presented in Figs. 6 and 7. In terms of formation heterogeneity, due to dense and conductive anomalies, Asmari Formation in the studied wells indicated various amounts of heterogeneity over the intervals. Lower part of zone 3, upper, middle and lower parts of zone 5 and lower part of zone 7.1 tended to be more heterogeneous. In addition to initial evaluations, five heterogeneity indices have been provided in well No. 126 which confirm the reservoir heterogeneities and are usable as valid inputs to all intelligent systems to different rock type or litho-type identifications (Fig. 11).

\subsection{Reservoir permeability}

This parameter was determined by textural analysis software, in addition to fracture analysis, for the studied reservoir. The connections were determined based on the conductive links in the matrix between the conductive features. However, the raw permeability indicator provided vague and relative permeability information. Zones 1, 3, 5 and 7-1 are the zones with the most permeability index $(>5)$, due to their high fracture density and aperture (Fig. 13). These zones for well No. 126 are listed in Table 2. Data from more wells are essential to establish a transformation function in order to obtain an absolute permeability profile for Asmari Formation. However, the calculated raw permeability for studied wells has been correlated by core and MDT data to consider as dependable data for reservoir evaluation.

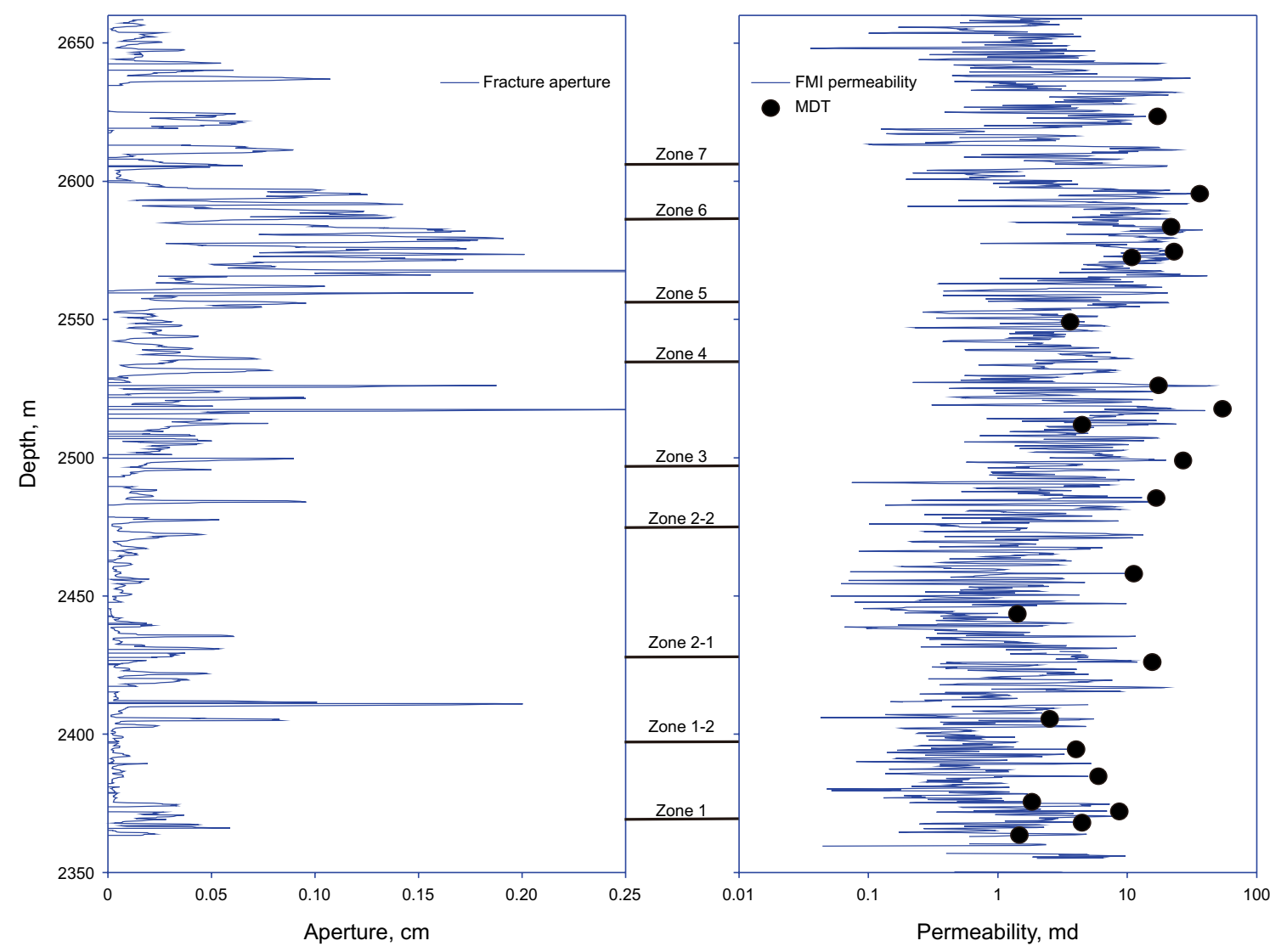

Fig. 13 Comparison between MDT data, FMI permeability and fracture aperture for well No. 126. Results indicate that permeability is controlled by fracture aperture, particularly in the highlighted zones 3 and 5 
Table 2 Calculated permeability index and secondary porosity for all zones

\begin{tabular}{|c|c|c|c|c|}
\hline Zones & Interval, $\mathrm{m}$ & Porosity distribution & Secondary porosity, $\%$ & $\begin{array}{l}\text { Average per- } \\
\text { meability, md }\end{array}$ \\
\hline Zone 1-1 & $2363-2396$ & $\begin{array}{l}\text { Moderate heterogeneous } \\
\text { With open fractures }\end{array}$ & $\sim 0-8$ & $\sim 0-8$ \\
\hline Zone 1-2 & $2396-2429$ & $\begin{array}{l}\text { Moderate heterogeneous } \\
\text { With open fractures }\end{array}$ & $\sim 0-6$ & $\sim 0-15$ \\
\hline Zone 2-1 & $2429-2471$ & $\begin{array}{l}\text { Moderate to high heterogeneous } \\
\text { With open fractures }\end{array}$ & $\sim 0-7$ & $\sim 0-11$ \\
\hline Zone 2-2 & $2471-2486.5$ & $\begin{array}{l}\text { Moderate to high heterogeneous } \\
\text { With open fractures }\end{array}$ & $\sim 0-7$ & $\sim 0-16$ \\
\hline Zone 3 & $2486.5-2530$ & $\begin{array}{l}\text { Moderate to high heterogeneous } \\
\text { With open fractures }\end{array}$ & $\sim 0-7$ & $\sim 0-50$ \\
\hline Zone 4 & $2530-2550.5$ & $\begin{array}{l}\text { Moderate heterogeneous } \\
\text { With open fractures }\end{array}$ & $\sim 0-7$ & $\sim 0-10$ \\
\hline Zone 5 & $2550.5-2585.5$ & $\begin{array}{l}\text { Moderate to high heterogeneous } \\
\text { With open fractures }\end{array}$ & $\sim 0-10$ & $\sim 0-25$ \\
\hline Zone 6-1 & $2585.5-2595$ & $\begin{array}{l}\text { Moderate to high heterogeneous } \\
\text { With open fractures }\end{array}$ & $\sim 0-6$ & $\sim 0-26$ \\
\hline Zone 6-2 & $2595-2605$ & $\begin{array}{l}\text { Moderate to high heterogeneous } \\
\text { With open fractures }\end{array}$ & $\sim 0-7$ & $\sim 0-16$ \\
\hline Zone 7-1 & $2605-2655$ & $\begin{array}{l}\text { Moderate to high heterogeneous } \\
\text { With open fractures }\end{array}$ & $\sim 0-7$ & $\sim 0-17$ \\
\hline
\end{tabular}

\subsection{Comparison of image log results with core and well data}

The main aim of this research was to indicate the reliability of electrical image logs for the evaluation of heterogeneous and fractured reservoirs as a replacement for core data. For this purpose, FMI and EMI were used to determine all fracture and reservoir parameters, and then, results were validated with core, production and well test data (Figs. 13, $14,16,17)$. Determination of fracture parameters is very important as they play an important role in the carbonate reservoirs.

After plotting porosity against permeability for core data, a lack of regression among these data indicated that
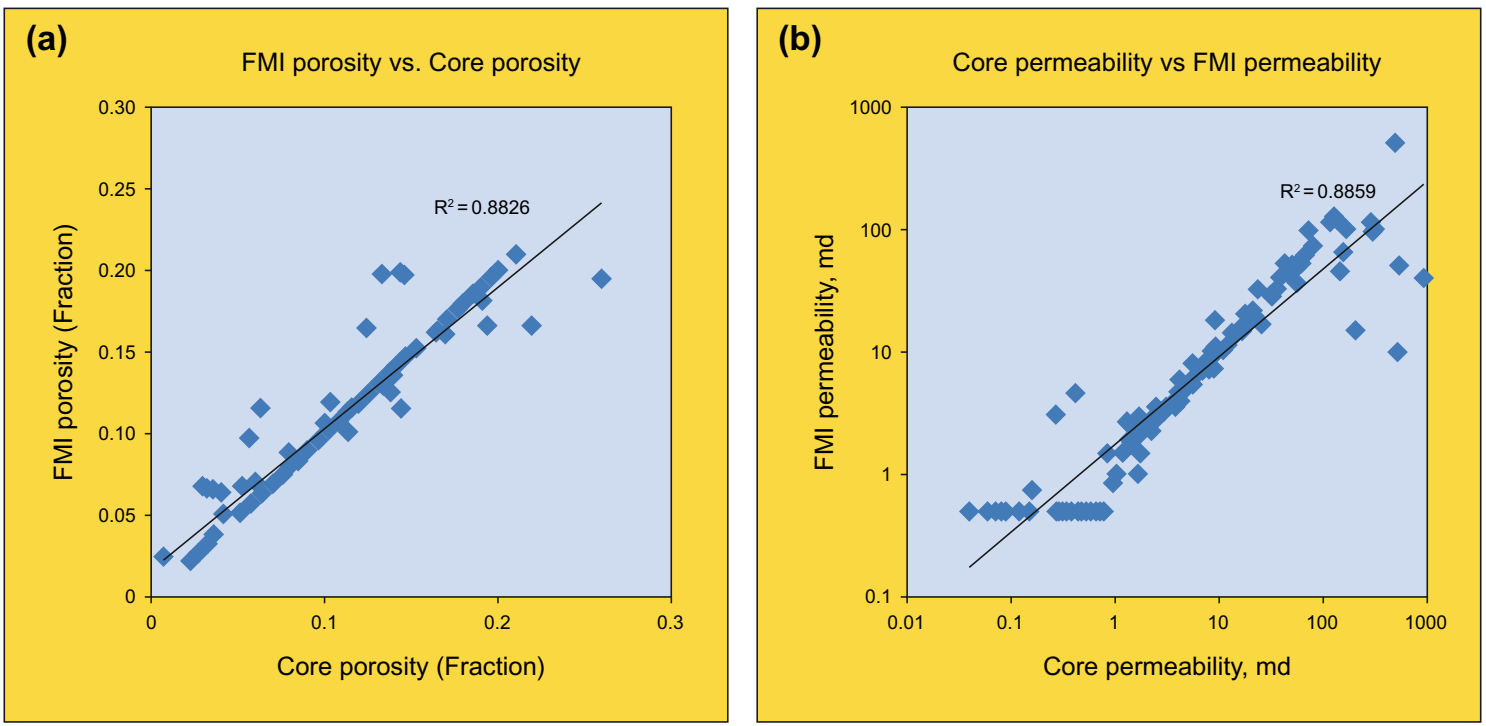

Fig. 14 Cross-plots for A: FMI and core porosity and B: FMI and core permeability. Data shows FMI may be considered as powerful tool for the calculation of reservoir parameters as well as fracture parameters 
permeability trend may be controlled by other factors. Therefore, fracture aperture, as the most pivotal parameter, was compared with permeability trend in Fig. 15. As could be seen, fracture aperture plays the most significant role on reservoir permeability which validated and confirmed by the MDT results (Fig. 13) mud loss data (Fig. 16) and five-year production data (Fig. 17). Further, core data and image logs were totally matched and FMI/EMI could produce continuous porosity and permeability logs with 0.1 inch resolution for all reservoir intervals.



Fig. 15 Cross-plot between FMI permeability and fracture aperture. High regression indicates that fracture aperture is the main parameter which is affected on reservoir permeability
Regarding the permeability, some zones, such as 1, 3 and 5 , show high permeability, due to their high fracture density and aperture. Meanwhile, a high number of vuggy fractures represented the role of dissolution in this reservoir. It seems that FMI and EMI represent the real fracture aperture better than core, because these tools could record fracture apertures in situ.

It is worth noting that overburden pressure could reduce fracture aperture. As illustrated in Figs. 12, 13, 14 and 15, measured fracture and reservoir parameters using image logs are absolutely reliable for reservoir evaluation. Furthermore, based on the production and mud loss data, both of the studied wells are mainly fractured, indicating a high production index in the studied field (Figs. 16, 17).

\section{Conclusion}

Electrical imaging tools (FMI and EMI) were used to detect the fractures and their impact on the reservoir properties, i.e., porosity and permeability, in the carbonate Asmari Formation (SW Iran) by comparing with core, production and well test data. The results of FMI and EMI analysis indicated that fracturing occurred in most intervals of the studied reservoir. It seems that the results of FMI and EMI for fracture evaluation are more reliable than core data due to low recovery factor for core in the fractured reservoirs. Also, image logs are able to provide porosity and permeability logs with

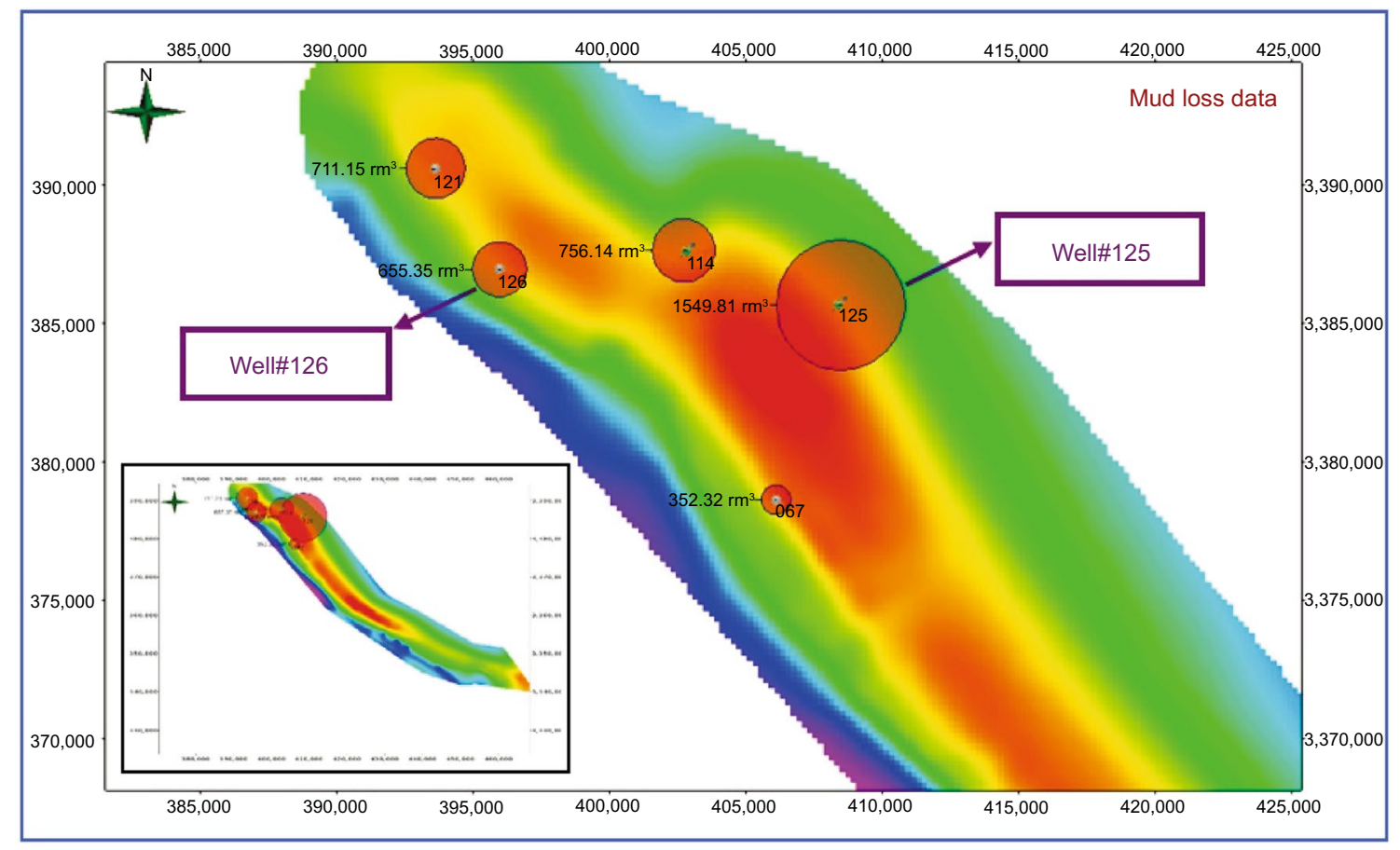

Fig. 16 Mud loss data for studied wells. More mud loss in well No. 126 may be related to dominance of longitudinal fractures which they show higher fracture aperture than other fracture sets. Mud loss data may be considered as a valid data for the determination of open fractures 


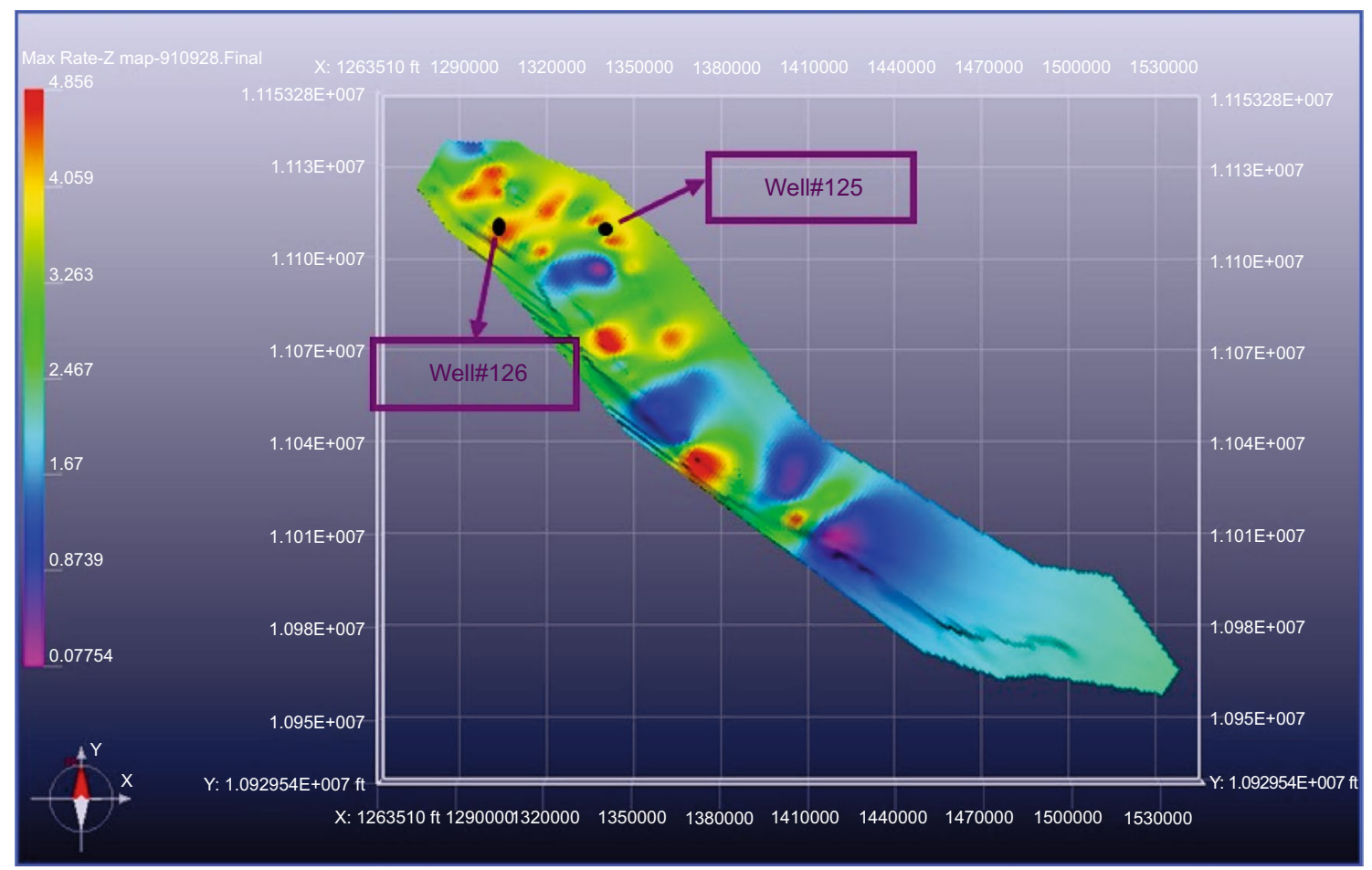

Fig. 17 Display of 3D map for production data in a 5-year period for studied wells. Both of the studied wells indicate high production index which may be related to the open fractures

0.1 inch resolution for all reservoir intervals. Discontinuous open fractures were regarded as the main part of the open fractures.

The dip of fractures in well No. 126 was dominantly at 60 degrees to N79E and strike N11W-S11E, while in well No. 125, their strike was N50W-S50E with 60 dip inclination toward S50W. Faulting-related fractures are widely observed in well No. 126 and their high fracture density is related to the axis recirculation by their around faults. Also, most detected fractures are open and longitudinal fracture set (with high aperture) is dominant fracture set in this field. Therefore, based on this salient point and the absence of any regression between core porosity and permeability, fracture aperture is considered as the most effective parameter on the reservoir properties, which strongly supported by MDT data. Secondary porosity is present in most intervals of the Asmari zones 1-1, 2-1, 2-2, 3, 5, 7-1, and thence high-heterogeneity-index intervals. Regarding the core and images data, this type of porosity varied between $0 \%$ and $10 \%$. However, FMI and EMI results indicated that the properties in most zones heavily rely on the secondary porosity, particularly fracture parameters. Some zones, such as zones 3 and 5 , with the most fracture density, represented a moderate to high-raw-permeability index. In conclusion, the results indicated that FMI and EMI can be considered as two powerful tools in detecting the fractures and calculating the reservoir parameters such as porosity and permeability. The present study indicated a high reliability of electrical image logs as a substitute for cores in the wells without core in the carbonate heterogeneous reservoirs of Zagros Basin.

Acknowledgements This research was made possible by the financial and data support from NISOC Oil Company. We acknowledge their support. The authors highly appreciate the effort of Dr. Bahman Soleimani and Miss Zohre Movahed for her contribution during this study.

Open Access This article is licensed under a Creative Commons Attribution 4.0 International License, which permits use, sharing, adaptation, distribution and reproduction in any medium or format, as long as you give appropriate credit to the original author(s) and the source, provide a link to the Creative Commons licence, and indicate if changes were made. The images or other third party material in this article are included in the article's Creative Commons licence, unless indicated otherwise in a credit line to the material. If material is not included in the article's Creative Commons licence and your intended use is not permitted by statutory regulation or exceeds the permitted use, you will need to obtain permission directly from the copyright holder. To view a copy of this licence, visit http://creativecommons.org/licenses/by/4.0/.

\section{References}

Aghli G, Fardin H, Mohamadian R, Saedi G. Structural and fracture analysis using EMI and FMI image log in the carbonate Asmari reservoir (Oligo-Miocene), SW Iran. J Geopersia. 2014;4(2):43-58. 
Aghli G, Soleimani B, Moussavi-Harami R, Mohammadian R. Fractured zones detection using conventional petrophysical logs by differentiation method and its correlation with image logs. J Pet Sci Eng. 2016;142:152-62.

Aghli G, Soleimani B, Tabatabai SS, Zahmatkesh I. Calculation of fracture parameters and their effect on porosity and permeability using image logs and petrophysical data in carbonate Asmari reservoir, SW Iran. Arab J Geosci. 2017;10(12):265.

Akbar M, Chakravorty S, Russell SD, Al Deeb MA, Efnik MRS, Thower R, et al. Unconventional approach to resolving primary and secondary porosity in Gulf carbonates from conventional logs and borehole images. In: Abu Dhabi international petroleum exhibition and conference Society of Petroleum Engineers; 2000.

Akbar M, Safarkhanlou Z, Tamimi M. Evaluation of Arab Formation using FMI data, Balal field. Ahvaz; 2003.

Alavi M. Regional stratigraphy of the Zagros fold-thrust belt of Iran and its proforeland evolution. Am J Sci. 2004;304(1):1-20.

Alavi M. Structures of the Zagros fold-thrust belt in Iran. Am J Sci. 2007;307(9):1064-95.

Ameen MS, MacPherson K, Al-Marhoon MI, Rahim Z. Diverse fracture properties and their impact on performance in conventional and tight-gas reservoirs, Saudi Arabia: the Unayzah, South Haradh case study. Am Assoc Pet Geol Bull. 2012;96(3):459-92.

Chandra V, Barnett A, Corbett P, Geiger S, Wright P, Steele R, et al. Effective integration of reservoir rock-typing and simulation using near-wellbore upscaling. Mar Pet Geol. 2015a;67:307-26.

Chandra V, Wright P, Barnett A, Steele R, Milroy P, Corbett P, et al. Evaluating the impact of a late-burial corrosion model on reservoir permeability and performance in a mature carbonate field using near-wellbore upscaling. Geol Soc Lond Spec Publ. 2015b;406(1):427-45.

Chen J, Wang S. Fracture detection in oil-based drilling mud using a combination of borehole image and sonic logs. Mar Pet Geol. 2017;84:195-214.

Corbett PWM, Geiger S, Borges L, Garayev M, Valdez C. The third porosity system understanding the role of hidden pore systems in well-test interpretation in carbonates. Pet Geosci. 2012;18(1):73-81.

de Jesus CM, Martins Compan AL, Surmas R. Permeability estimation using ultrasonic borehole image logs in dual-porosity carbonate reservoirs. Petrophysics. 2016;57(06):620-37.

DeMets C, Gordon RG, Argus DF. Geologically current plate motions. Geophys J Int. 2010;181(1):1-80.

Halliburton. Electrical micro imaging service (sales kit). Houston: Halliburton; 1996.

Hornby BE, Luthi SM, Plumb RA. Comparison of fracture apertures computed from electrical borehole scans and reflected Stoneley waves: an integrated interpretation. Log Anal. 1992;33(01).

Khoshbakht F, Memarian H, Mohammadnia M. Comparison of Asmari, Pabdeh and Gurpi Formation's fractures, derived from image log. J Pet Sci Eng. 2009;67(1-2):65-74.

Khoshbakht F, Azizzadeh M, Memarian H, Nourozi GH, Moallemi SA. Comparison of electrical image log with core in a fractured carbonate reservoir. J Pet Sci Eng. 2012;86-87:289-96.

Lai J, Wang G, Fan Z, Chen J, Qin Z, Xiao C, et al. Three-dimensional quantitative fracture analysis of tight gas sandstones using industrial computed tomography. Sci Rep. 2017a;7(1):1825.

Lai J, Wang G, Fan Z, Chen J, Wang S, Fan X. Sedimentary characterization of a braided delta using well logs: the Upper Triassic Xujiahe Formation in Central Sichuan Basin, China. J Pet Sci Eng. 2017b;154:172-93.

Lavenu APC, Lamarche J, Salardon R, Gallois A, Marié L, Gauthier BDM. Relating background fractures to diagenesis and rock physical properties in a platform-slope transect. Example of the Maiella Mountain (central Italy). Mar Pet Geol. 2014;51:2-19.

Luthi SM, Souhaite P. Fracture apertures from electrical borehole scans. Geophysics. 1990;55(7):821-33.

Lyu W, Zeng L, Liu Z, Liu G, Zu K. Fracture responses of conventional logs in tight-oil sandstones: a case study of the Upper Triassic Yanchang Formation in southwest Ordos Basin, China. Am Assoc Pet Geol Bull. 2016;100(9):1399-417.

Martinez LP, Hughes RG, Wiggins ML. Identification and characterization of naturally fractured reservoirs using conventional well logs. The University of Oklahoma; 2002. 23p.

McQuillan H. Fracture patterns on Kuh-e Asmari Anticline, Southwest Iran. Am Assoc Pet Geol Bull. 1974;58(2):236-46.

Miller DJ, Iturrino GJ, McGuire JC. Corelog correlations in oceanic basement from Hole 1105A on the Southwest Indian Ridge. In: Proceedings of the ODP, Scientific Results; 2003. p. 1-29.

Movahed Z, Junin R, Bakhtiari HA. The effect of tar on the petrophysical analysis of FMI in Asmari fractured reservoir. In: ICIPEG 2014. Springer; 2015a. p. 239-45.

Movahed Z, Junin R, Bakhtiari HA, Safarkhanlou Z, Movahed AA, Alizadeh M. Introduction of sealing fault in Asmari reservoir by using FMI and RFT in one of the Iranian naturally fractured oil fields. Arab J Geosci. 2015;8(12):10919-36.

Nelson R. Geologic analysis of naturally fractured reservoirs. New York: Gulf Professional Publishing; 2001.

Özkaya SI. Fracture length estimation from borehole image logs. Math Geol. 2003;35(6):737-53.

Rezaee MR, Chehrazi A. Fundamentals of well log interpretation. 1st ed. Tehran: University of Tehran; 2005 (in Persian).

Saboorian-Jooybari H, Dejam M, Chen ZJ, Pourafshary P. Fracture identification and comprehensive evaluation of the parameters by dual laterolog data. In: SPE Middle East unconventional resources conference and exhibition. Society of Petroleum Engineers; 2015.

Schlumberger. GeoFrame 4.2, BorView user's guide. Houston: Schlumberger Ltd; 2005.

Schlumberger. Using borehole imagery to reveal key reservoir features. In: Reservoir optimization conference, Tehran, Iran; 2003.

Serra O. Formation MicroScanner image interpretation. Houston: Schlumberger Educational Services; 1989.

Serra O, Serra L. Well logging: data acquisition and applications. Paris: Editions Technip; 2004a.

Serra O, Serra L. Well logging: data acquisition and applications. France: Serralog; 2004b.

Stocklin J. Structural history and tectonics of Iran: a review. Am Assoc Pet Geol Bull. 1968;52(7):1229-58.

Thompson LB. Fractured reservoirs: integration is the key to optimization. J Pet Technol. 2000;52(02):52-4.

Tingay M, Reinecker J, Müller B. Borehole breakout and drillinginduced fracture analysis from image logs. World Stress Map Project; 2008. p. 1-8.

Tokhmchi B, Memarian H, Rezaee MR. Estimation of the fracture density in fractured zones using petrophysical logs. J Pet Sci Eng. 2010;72(1):206-13.

Van der Land C, Wood R, Wu K, van Dijke MIJ, Jiang Z, Corbett PWM, et al. Modelling the permeability evolution of carbonate rocks. Mar Pet Geol. 2013;48:1-7.

Witherspoon PA. Validity of cubic law for fluid flow in a deformable rock fracture. Berkeley: Lawrence Berkeley Natl. Lab; 2010.

Zazoun RS. Fracture density estimation from core and conventional well logs data using artificial neural networks: the CambroOrdovician reservoir of Mesdar oil field, Algeria. J Afr Earth Sci. 2013;83:55-73. 